San Jose State University

SJSU ScholarWorks

$5-1-2004$

\title{
Staff Perceptions of Workload and Care Requirements for Incontinent Patients in Long-term Care Settings
}

Amy M. Crickmer

San Jose State University

Follow this and additional works at: https://scholarworks.sjsu.edu/etd_projects

Part of the Other Nursing Commons

\section{Recommended Citation}

Crickmer, Amy M., "Staff Perceptions of Workload and Care Requirements for Incontinent Patients in Long-term Care Settings" (2004). Master's Projects. 756.

DOI: https://doi.org/10.31979/etd.v78n-ezzt

https://scholarworks.sjsu.edu/etd_projects/756

This Master's Project is brought to you for free and open access by the Master's Theses and Graduate Research at SJSU ScholarWorks. It has been accepted for inclusion in Master's Projects by an authorized administrator of SJSU ScholarWorks. For more information, please contact scholarworks@sjsu.edu. 


\section{SAN JOSE STATE UNIVERSITY}

SCHOOL OF NURSING

\section{MASTER'S PROGRAM PROJECT OPTION (PLAN B) PROJECT SIGNATURE FORM}

STUDENT NAME

SEMESTER ENROLLED

Amy Cridemar
Spring oy

\section{TITLE OF PROJECT}

Staff perceptions of workload and cave requirements for incontinent pationts in long-term care setting

\section{NAME OF JOURNAL}

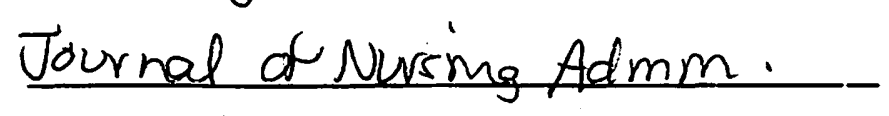

The project and the manuscript have been successfully completed and meet the standards of the School of Nursing University. The project demonstrates the application of professional knowledge, clinical expertise, and scholarly thinking. An abstract of the project and two copies of the manuscript are attached.

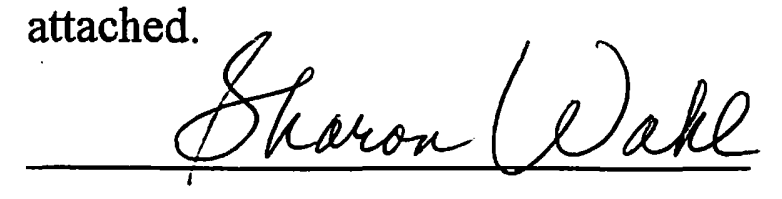

ADVISOR'S SIGNAURE

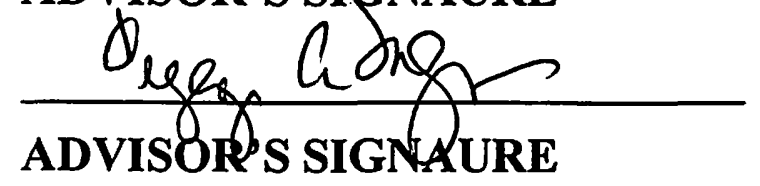

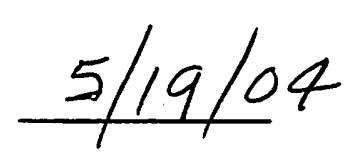

DATE

$05 / 20 / 04$

DATE

Please submit the form to the Graduate Coordinator. Attach abstract, two copies of the manuscript, and the documentation of submission to the journal (i.e., postal receipt). 
Staff Perceptions of Workload and Care Requirements for Incontinent Patients in Long-term Care Settings

-Amy M Crịckmer MS, RN

San Joșe Sțate Univiverșity

School of Nursing

In Partial Fulfillment of the MS program

May 19.2004 
Staff Perceptions of Workload and Care Requirements for Incontinent Patients in Long-term Care settings

Introduction

In response to the Omnibus Reconciliation Act (OBRA) mandate "to ensure that a resident who is incontinent of bladder receives the appropriate treatment and services to restore normal bladder functioning..." (Department of Health and Human Services (DHHS), 1989, p.5333), several studies were designed and implemented to demonstrate that incontinence interventions worked. The research also showed that staff behaviors did not change and toileting programs were not carried forward once studies were completed. What was missing from the research was any mention that certified nursing assistants (CNAs) were asked to participate in the planning phase of an incontinence program. The purpose of this study was to ask CNAs what they thought comprised a doable toileting program and how they could incorporate the changes necessary into their schedules to accommodate the amount of work toileting programs entail.

\section{Incontinence Management Strategies}

All types of toileting interventions are effective (Colling, Ouslander, Hadley, Eisch, and Campbell, 1992; Creason, et al., 1992; Schnelle, Newman, Fogarty, Wallston, and Ory, 1991; Schnelle, et al., 1993). Also demonstrated by the studies is that permanent changes in staff behavior were not effected and residents were not being toileted after the studies were completed (Colling et al.; Schnelle, Newman, and Fogarty, 1990). Staff gave many reasons for non-compliance with the protocol, including "too hard to change routines, better to change residents than to bother them with toileting, and too difficult or too demented to be toileted" (Colling, et al. p. 139). Mather and Bakas 
(2002) found that certified nursing assistants (CNAs) identified four major barriers to continence management: excessive workloads, inconsistent cooperation from other staff, inadequate communication, and lack of team work.

The research done by Schnelle et al. (1990) on the management of patient continence in long-term care (LTC) facilities found similar problems with the implementation of a timed-voiding program. The staff continued to change residents rather than toilet them even when a 2-hour toileting schedule resulted in high levels of continence. "Patient continence is not an adequate reinforcer that leads staff to produce the work behavior that will lead to continence maintenance. In addition, in-service training and written protocols describing desired patient continence care are also apparently not sufficient interventions" (p. 375).

\section{Research Problem}

There exists a demonstrable gap between the ability to decrease incontinent episodes in long-term care residents and the implementation of the procedures necessary to do so. In light of the research by $\mathrm{Yu}$ (1991) revealing the stress that staff feels while working with incontinent residents, it is of interest that the caregivers are not more active in employing all possible methods to decrease incontinent episodes.

The purpose of this study was to explore what nursing aides perceived as barriers to implementing a toileting program to decrease incontinence. The goal was to identify what changes CNAs needed to implement a patterned toileting program. 


\section{Research Questions}

What are the opinions of staff about toileting patients? What changes would be necessary in order for the nursing aides to be willing to toilet patients as part of their daily routines? What do they perceive they would need in order to accomplish this task?

\section{Methods}

Focus group interviews were conducted for this exploratory study to evaluate CNAs' feelings about toileting patients and how this could be achieved given their workload. CNAs with a current license were interviewed in two Northern California LTC facilities over two shifts. One nursing home had 130 beds and the other had 65. Both were for-profit facilities.

Group meetings were advertised by fliers posted throughout the facility and by administrators requesting staff participation. Each interview was advertised as lasting one hour. Five sessions were scheduled, but despite being offered $\$ 20.00$ for their time, no one came to three of the sessions. When questioned as to why they did not want to participate, reasons verbalized for not participating included "too tired" and "I have to go to my other job." Many CNAs seemed suspicious of the motivation for the interviews.

A total of two interviews were performed. One interview had nine participants and the other had three for a convenience sample of twelve people (ten women and two men). All worked day shift, one floated to evening shift, and two floated to night shift. CNA work experience ranged from three months to seventeen years. The mean work experience was three years and the average was four years. Informed consent was obtained from each participant. Date regarding ages and ethnicity was not collected. 
Each interview was tape-recorded and transcribed verbatim. Individual transcripts were analyzed for trends, patterns, and recurring themes and results were confirmed by another researcher. Since each session was tape-recorded and no names were used, it was not possible to tell who was making which comment and confidentiality was assured.

\section{Findings}

All CNAs reported liking their jobs and felt a great deal of accomplishment and pride in taking care of people. But what they wanted to talk about instead of toileting programs was how they were feeling about change and about the impossible burden they shoulder on a daily basis. Where the research had started out as a project for CNA input into incontinence programs and planning, this is not the information that emerged. During the data gathering phase, the theoretical model veered from a patient centered focus to a staff centered one. Overwork was the major theme that come out of this investigation.

Each CNA reported taking care of at least nine people on day shift; on the evening and night shift, the CNAs reported taking care of as many as twenty-four patients. All CNAs reported they understood the importance of continence care and would like to provide higher quality care but, without exception, all CNAs participating in the study felt that they were already overburdened and felt that too much was expected from them. "Some people don't care that you hurt, they don't care, they just want more and more and more work." They felt they did not have time to provide basic care. "Sometimes if I work P.M. shift, I have fifteen patients and no, I cannot toilet people. I am trying to feed them and change the diapers a few times." The CNAs felt that the licensed nursing staff also carried a heavy burden, and consequently, the CNAs did not 
look to the licensed staff to provide assistance. This is supported by Mather and Bakas (2002) who report that CNAs felt that the nursing staff was too bogged down with paper work to provide direct patient care. The CNAs also felt that other CNAs were too busy with their own patient load to provide back-up help.

All CNAs identified workload as the primary barrier to implementing any schedule changes that required increased patient care. The only way the CNAs could conceive of being able to toilet patients was to either reduce the number of patients they were caring for or have someone else responsible for toileting patients. Lekan-Rutledge, Palmer, and Belyea (1998) found that CNAs' perception of obstacles to voiding programs included increased workload, nursing staff absenteeism, and staff turnover. The annual turnover rate of nursing aides is estimated from $40 \%$ (Burgio and Burgio, 1990) to $100 \%$ (Gallardo, 2001; Van Kleunen and Willner, 2000). Additional workload and stress may increase the turnover rate for CNAs (Burgio and Burgio). "I love the patients, I like my job, but it's too much, and now to toilet? I can't think how to do this and everything else, too. I try, I try hard to be so good."

Research questions number two and three are not well addressed but this is not an oversight. The CNAs were so appalled by the idea that more work might be asked of them, they could not get beyond the first question. Every time the discussion was directed to the other research questions, the $\mathrm{CNAs}$ returned to the first question. They would ask when the incontinence program would be starting, what would they have to do, and how it would affect them. "If they try to make me do all this and toilet, I think I will leave. Maybe I work somewhere else, maybe I get another job, do something else." They 
were clearly upset by what they perceived as an imminent change in their job descriptions despite several explanations during the interviews that the purpose of the interview was purely research, a project collecting information about toileting programs.

\section{Application to Practice}

After talking with the CNAs about toileting programs and implementation, it became evident that what the CNAs wanted to talk about was how they were feeling in the face of being told that their efforts were not enough and more work may be expected of them. Because of this, job satisfaction and organizational impact were further discussed, and, based on the data from the interviews, a pattern emerged, consistent with descriptions in the literature, that these CNAs may be demonstrating burnout behaviors associated with the breaking of the "psychological contract" (Rousseau, 1995).

The psychological contract, as, defined by Rousseau (as cited in Maslach, Schaufeli, and Leiter, 2001, p. 409) is, "The belief in what the employer is obliged to provide based on perceived promises of reciprocal exchange." In other words, CNAs perceive they are being required to give more in terms of time, skills, and effort, but receive less in terms of pay, benefits, and job security. Each time the psychological contract is broken, it is the CNAs who suffer the consequences with the inevitable result of discouragement, increased stress, decreased job satisfaction, and high job turnover. (Maslach et al.)

Karasek (as cited in Laschinger, Finegan, Shamian, and Wilk, 2001, p. 262). reports that job stressors include the hectic nature of the job, how fast and how hard one must work to perform the job, amount of time available in relation to the amount of work to be done, the amount of work performed under pressure, the presence of conflicting 
time demands, how often the work is interrupted or slowed by others (families, other staff, patients, etc.), and the amount of concentration the work requires.

CNAs are being told to work harder but no matter how hard they work, it is not enough. Maslach et al. (2001) found that people are more tolerant of increased workloads if they are well paid and feel their work is valuable and important. CNAs earn, on an average, between $\$ 7.51$ and $\$ 10.59$ and hour which puts them near or below the federal poverty line (United States Department of Labor Statistics, 2003). "In today's economy, there are many lower-skilled jobs that pay more and demand less than positions in long-term care... wages are being outpaced by jobs in other sectors like retail and hospitality." (Van Kleunen and Willner, $\mathrm{p}_{\ldots 1} 18$ )

CNAs are paid very little, benefits are cut, and those remaining cost more. The CNA's workload has also increased with no promise by the facility of something better to off-set the cost to the worker. There is a widening gap between what caregivers are being required to do and the care they are physically able to provide. Work situations and chronic overwhelming demands contribute to exhaustion and are likely to erode a person's sense of effectiveness. "It is difficult to gain a sense of accomplishment when feeling exhausted or when helping people toward whom one is indifferent" (Maslach et al.,2001, p.403)

There are six activities of daily living (ADL): feeding, dressing, bathing, transferring, toileting, and walking. There is a hierarchal pattern to ADL loss. With the exception of continence, the typical pattern of loss begins with bathing and then moves to dressing, toileting, transferring, and feeding. (DHHS, 2000). The average number of ADL limitations for nursing home residents is 4.7 . Mental disability also impacts a 
person's ability to participate in any level of self care activity. The number of nursing home residents with cognitive impairment ranges between $75 \%$ and $86 \%$ who, because of various dementias, are likely to be resistant to care (DHHS). Currently, CNAs in LTC facilities report they are responsible for up to 20 patients each shift (American Federation of Teachers, 2002). $\quad$ (Insert Figure 1)

As of 1997, the average daily rate for nursing home care in the United States was $\$ 125.00$ ( $\$ 45,625$ per year) and the average individual expenditure for nursing home care for people requiring LTC was $\$ 50,000$ annually (American Association of Retired People, 1998). Nearly $70 \%$ of LTC residents are covered by Medicaid (Lee and Haaga, 2002). In fiscal year 1998, Medi-Cal (California's Medicaid system) expenditures for LTC were $\$ 31,000$ per patient (Understanding Medi-Cal: Long Term Care, 1999). Thus, there is a gap of approximately $\$ 19,000$ between the cost of caring for a patient at a forprofit LTC facility and what the LTC facilities are reimbursed for patient care.

Increasing federal and state regulations also absorb money that could be better spent improving the quality of care in LTC facilities. Van Kleunan and Wilner (2000) note that when planning policy changes, the Health Care Finance Administration (HCFA) looks at the amount of paperwork that any.new regulation would generate as well as the potential benefit of the policy change to consumers and providers but they do not calculate other costs. "What's more, federal healthcare agencies do not take 'labor impact' into account when proposing changes in long-term care policy" (Van Kleunan and Wilner, p. 120). This means that HCFA does not assess if these policy changes will affect staffing, wages, or cause workforce upheaval for the people who provide the care and implement the policy changes. 
As of $2001,12.6 \%$ of Americans were 65 or older but this should rise to $20 \%$ by 2030 (CAHF Facts and Statistics, 2002). Piotrowski (2003) predicts we will need triple the number of CNAs to provide care at current levels; the demand for CNAs should increase from 1.9 million to 5.7 million by 2050 . Piotrowski estimates that residents of United States nursing homes will increase to four times the current level by 2030 . Per the United Nations Population Fund, the population of the U.S. as a whole will increase $40 \%$ by 2050 . So while there will be a four fold increase in the population of Americans who need LTC by 2030, there will not be a corresponding increase in the working age population. Lee and Haage (2002) predict that health care costs will grow more quickly than the economy as a whole. By fiscal year 2040, federal expenditures for Social Security, Medicare, and Medicaid will account for approximately $20 \%$ of the Gross Domestic Product compared to $7.5 \%$ in fiscal year 2000. Federal Reserve Chairman, Alan Greenspan, stated on February 25, 2004 in his testimony before the House Budget Committee, "This dramatic demographic change is certain to place enormous demands on our national resources-demands we will be unable to meet unless action is taken." He testified that the best way to deal with the exploding deficit is though spending cuts.

(Insert figure 2)

\section{Recommendations}

The amount of work we can expect from a human being in an eight hour shift is finite. Registered nurses need to speak out not only for vulnerable patients but for vulnerable staff as well. We can deal with the crises now by exploring alternate solutions or we can continue to define unrealistic standards for quality care and continue to raise 
expectations and deal reactively with the labor crisis as it unfolds. Nurses, as a community, need to discuss how we are going to provide even basic care to LTC patients.

We have a window of opportunity of about a decade during which the percentage of working age people will be at record highs. (The Economist, 2004). Despite the favorable employment climate, few LTC facilities are able to retain staff or consistently fill open CNA positions. A person admitted to a LTC facility for reasons other than rehabilitation is not likely to benefit, in the long term, from labor-intensive restorative care. With a shrinking federal budget, increasing costs of care, and an impending decrease in the labor pool, healthcare administrators should be looking at what could be cut from the nursing assistant workload, not what will increase their burden.

In geriatric settings, the nursing assistant delivers $90 \%$ of patient care. CNAs have little to no status in the health care community, get little to no respect and make poverty wages. In addition, they have very little input into decision-making about schedules and workloads. Per Newman (1997), the 1996 Agency for Health Care Policy and Reform guidelines encourage nursing home administrators to include direct caregivers in the development of continence programs and other programs affecting ADL care. Maslach et al. (2001) report that burnout is higher for people who have little participation in decision making. Therefore, in an effort to decrease burnout and as part of the retention efforts by nursing for LTC staff, CNAs need to be the primary source of information and planning for future guidelines and health policies in terms of care in LTC facilities.

We need to increase the CNAs' presence in policy decisions in order to increase the CNA's sense of their value and importance in a LTC facility. We also need to 
increase financial reimbursement in an effort to retain current staff or recruit new staff. Because there is no money to increase wages, other forms of financial gain are available, including tax credits for health care workers and vouchers for childcare, housing, and transportation. Also needed is flexible scheduling and self-scheduling in an effort to make the CNA job as attractive as possible. (Insert figure 3)

Improvements in technology can decrease actual labor, ease delivery of care, decrease injury, and increase efficiency. More Medicaid payments for ADL care could be relocated to patients' homes and their communities to support elderly people's families and care-takers in an effort to allow people to age in place. LTC facilities can be relocated from urban areas to rural areas and to former manufacturing centers where labor costs are lower and unemployment is higher. Comprehensive retirement communities could be built in high unempleyment areas of the US.

CNAs themselves suggest higher staffing or delegating other staff to toilet patients in an effort to ease their workload. This is consistent with the suggestions by Maslach that people need to make decisions about work and feel empowered when they are allowed to do so. This is an obvious suggestion and further research is needed into what CNAs suggest and how to structure their ideas.

Conclusion

Twelve CNAs cannot speak for 1.9 million CNAs, but the data is clear. Nationwide, CNAs are overburdened and overwhelmed. This group of twelve spoke eloquently and sincerely about the pressures they feel and the stress that their expanding workload causes them. There is little incentive for them to remain employed as CNAs and there is little to entice new workers into this already critically understaffed area. If we 
continue to ignore the worker situation, it will continue to escalate throughout the next four decades.

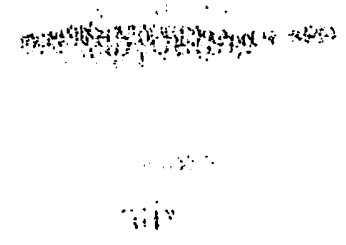

and $\because \div$ 


\section{High CNA Turnover}

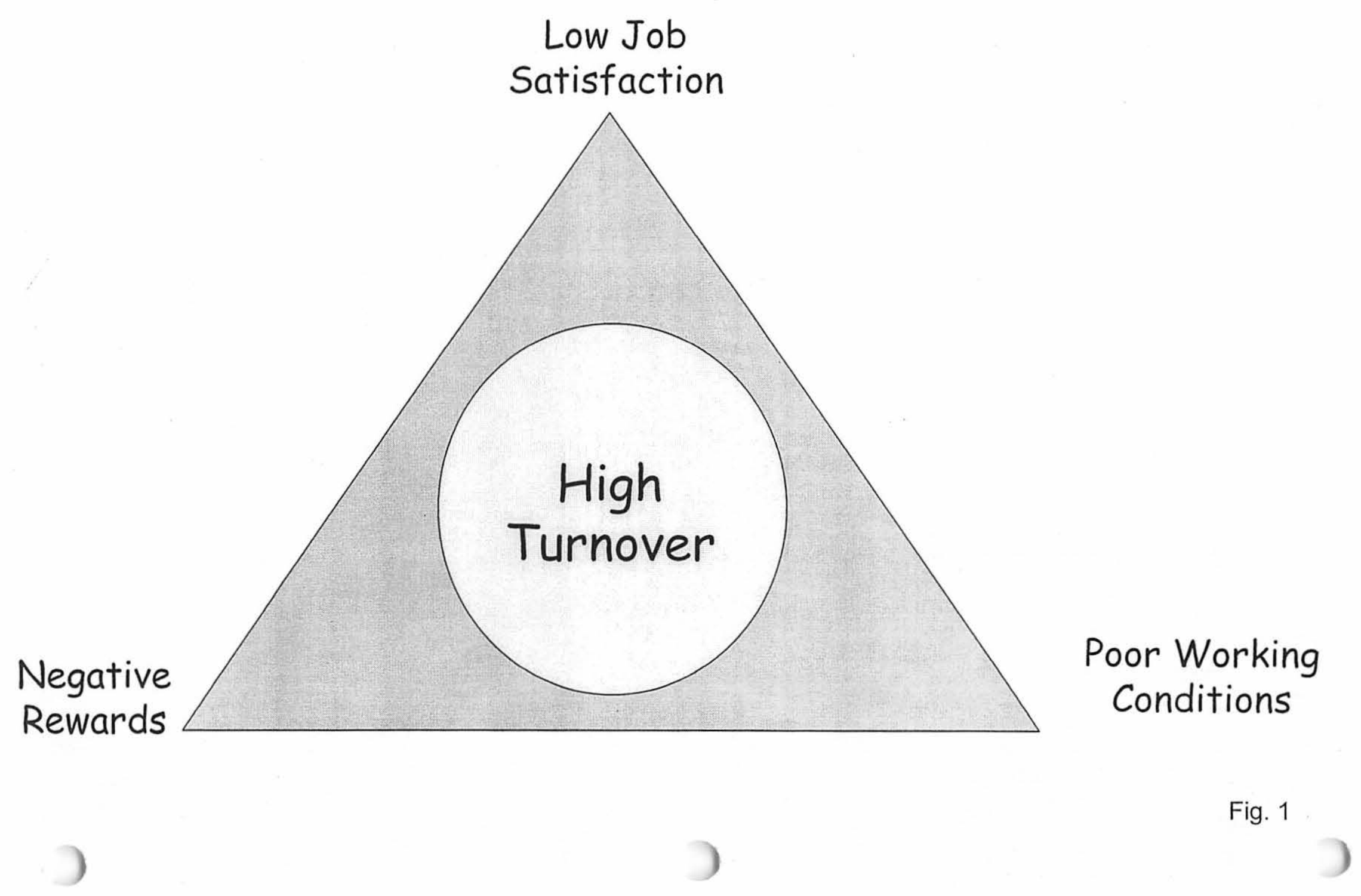




\section{Long Term Care Crises}

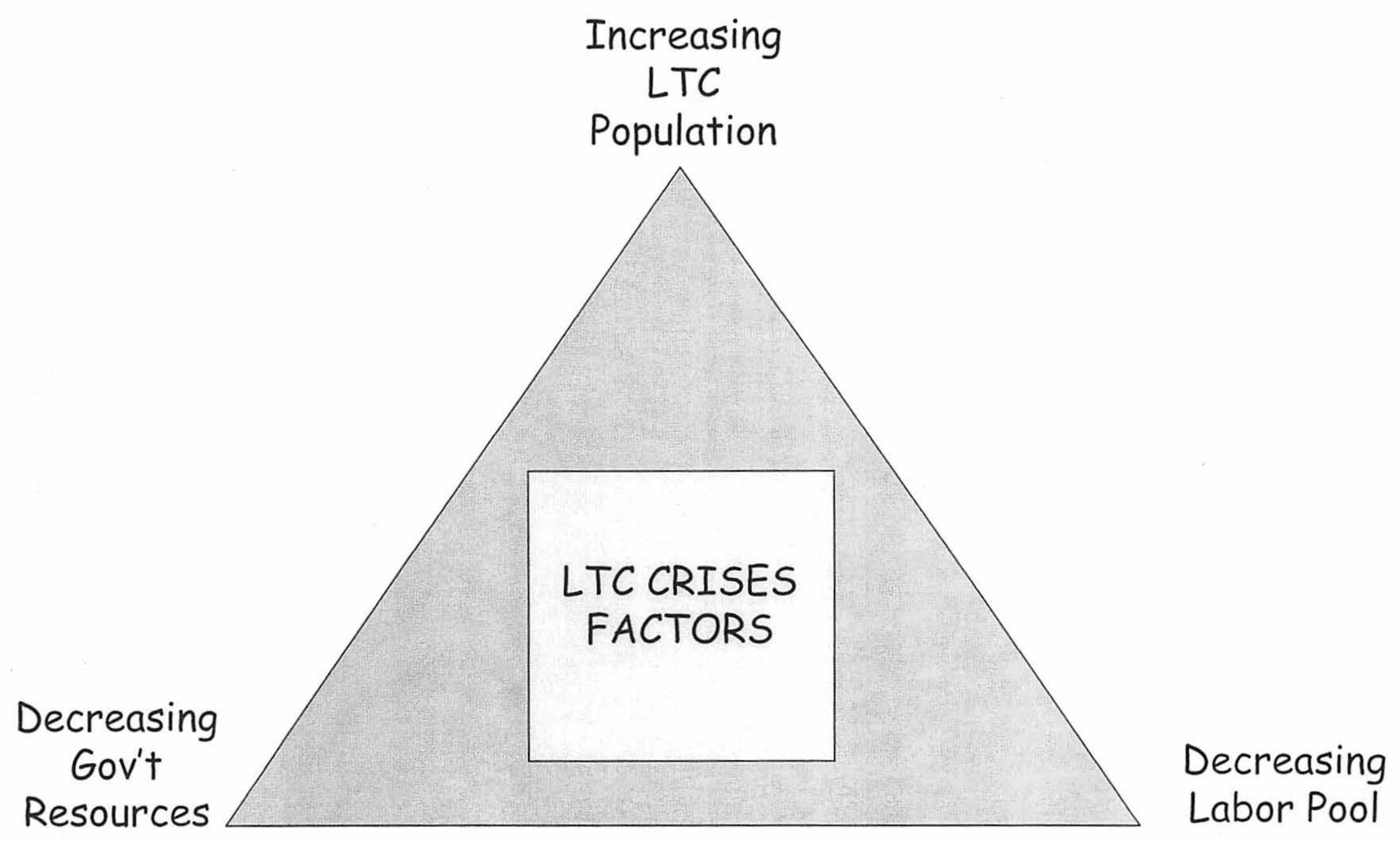

Fig. 2 


\section{Organizational Commitment}

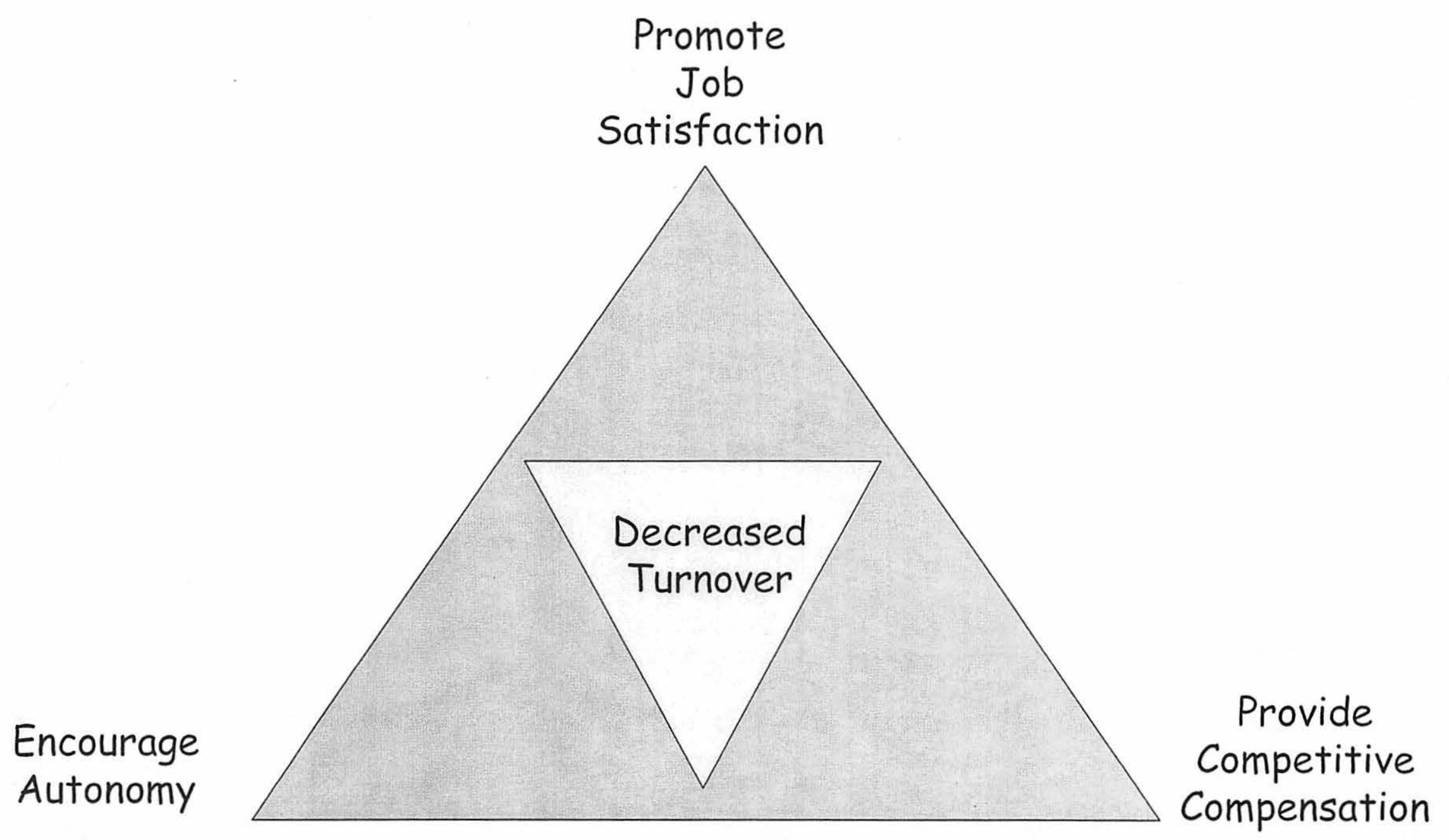

Fig. 3 


\section{References}

American Association of Retired People, (1998). The status of medicare part A and B trust funds: The trustees' 2004 annual report. Retrieved April 1.2004, from http//research.aarp.org/health/dd96_medicare.html American Federation of Teachers (2002). It's not just nurses anymore: Survey of three other health occupations finds patient safety at risk due to understaffing._Press Releases. Retrieved March 31, 2004, from Http://www.aft.org/press/2002/041102.html Burgio, L. D., \& Burgio, K. L. (1990). Institutional staff training and management: A review of the literature and a model for geriatric, lont-term-care facilities International Journal of Aging and Human Development, 30, (4) 287-302.

CAHF facts and stats: Long-term care providers. Retreived January 30, 2004, from

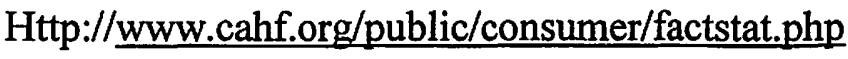

Colling, J., Ouslander, J., Hadley, B. J., Eisch, J., \& Campbell, E. (1992). The effects of patterned urge-response toileting (PURT) on urinary incontinence among nursing home residents. Journal of the American Geriatrics Society, 40, 135-141.

Creason, N.S., Grybowski, J.A., Burgener, S., Whippo, C., Yeo, S., and Richardson, B. (1989). Prompted voiding therapy for urinary incontinence in aged female nursing home residents Journal of Advanced Nursing, 14, 120-126

Department of Health and Human Services, (1989). Rules and regulations: Urinary incontinence. Federal register 54 (21), 5333-5334

Department of Health and Human Services, Public Health Service, (1996). Urinary incontinence in adults. (AHCPR) Publication No. 92-0628. Rockville, MD: Author 
Department of Health and Human Services (2000). Retreived February 5, 2004, from http://aspe.os.dhhs.gov/daltcp/reports/nhalfuse.htm

The Economist magazine, (2004). An Aging Society, March 13-19 p.57

Galloro, V. (2001) . Staffing outlook grim. Modern Healthcare, 31, 8, 64

Greenspan, Allen (2004). Testimony before the house budget committee 2/24/2004

Retreived February 25, 2004 from http://www.msnbc.com/id/4371103

Laschinger, H.K., Finegan, J., Shamian, J.\& Wilk, P. (2001). Impact of structural and psychological empowerment on job strain in nursing work settings: Expanding Kanter's model. Journal of Nursing Administration, (31), 5, 260-272

Lee, R. and Haaga, J. (2002). Government spending in an older America. Population Reference Bureau; Reports on America, (3), 1, 1-16

Lekan-Rutledge, D., Palmer, M. H., \& Belyea, M. (1998). In their own words: Nursing assistants' perceptions of barriers to implementation of prompted voiding in long-term care. The Gerontologist, 38, (3) 370-378.

Maslach, C., Schaufeli, W.B., \& Leiter, M.P. (2001). Job burnout. Annual Review of Psychology 52:397-422

Mather, K.F. \& Bakas, T. (2002). Nursing assistants' perception of their ability to provide continence care. Geriatric Nursing 23, (2), 76-87

Newman, D.K. (1997). What's new: The AHCPR guideline update on urinary incontinence. Journal of Ostomy and Wound Management, 42, (10):46-59

Piotrowski, J. (2003). Who will care for the elderly. Modern Healthcare, 33, (24). 32 
Schnelle, J. F., Newman D. R., \& Fogarty, T. (1990). Statistical quality control in nursing homes: Assessment and management of chronic urinary incontinence. Health Services Research, 25, (4) 627-637..

Schnelle, J.F., Newman, D.R., Fogarty, T.E., Wallston, K. \& Ory, M. (1991). The assessment and quality control of incontinence care in long-term care cursing facilities. Journal of the American Geriatrics Society, 39, (2), 165-171

Schnelle, J. F., Newman, D., White, M., Abbey, J., Wallston, K. A., Fogarty, T., \& Ory M. G. (1993). Maintaining continence in nursing home residents through application of industrial quality control. The Gerontologist, 33, (1) 114-121

Understanding MediCal: Long term care (1999) Retreived January 12, 2004, from http://www.chhs.ca.gov/longtermcare.html United Nations Population Fund, 2001. Total population by country, 1950, 2000, 2015, 2025, 2050 (Medium-fertility variant) Retreived April 14, 2004 from http//www.photius.com/rankings/world2050_erank.. United States Department of Labor Statistics. Retreived April 23, 2004, from http://www.allalliedhealthschools.com/faqs/ona.php Van Kleunen, A. \& Wilner, M.A. (2000). Who will care for mother tomorrow? Journal of Aging and Social Policy, 11, (2-3), 115-126

Yu, L. C. (1991). Urinary incontinence: Nursing home staff reaction toward residents. Journal of Gerontological Nursing, 17, (11) 34-41. 